Available online at

http://journal.ugm.ac.id/jifnp
INDONESIAN FOOD AND NUTRITION PROCRESS

Indonesian Food and Nutrition Progress, 2017, Vol. 14, Issue 1

\title{
Determination of Antioxidant Activity and Phenolic Compounds of Methanolic Extract of Java Plum (Syzygium cumini Linn.) Seed
}

\author{
Rohadi $^{\left.1,2^{*}\right)}$, Umar Santoso ${ }^{2)}$, Sri Raharjo ${ }^{2)}$, lip Izul Falah ${ }^{3)}$ \\ ${ }^{1)}$ Department of Processing Agricultural Product, Faculty of Agricultural Technology, Semarang University, \\ Semarang, Indonesia \\ ${ }^{2)}$ Department of Food and Agricultural Product Technology, Faculty of Agricultural Technology, Universitas \\ Gadjah Mada, Yogyakarta, Indonesia \\ ${ }^{3)}$ Department of Chemistry, Faculty of Mathematics and Natural Science, Universitas Gadjah Mada, \\ Yogyakarta, Indonesia \\ ${ }^{*}$ Corresponding author, email address: rohadij@yahoo.com
}

Received 23 Jan 2017; Accepted 12 May 2017; Published Online 15 May 2017

\begin{abstract}
Methanolic extract of Java plum (Syzygium cumini L.) seed (MEJS) is a potential source of natural antioxidant. As indicated by several in vitro measurements, the extract had strong DPPH (1,1 diphenyl, 2-picryl hydrazyl) and ABTS (2,2-azinobis, 3-ethylbenzothiazoline-6-sulphonate) radical scavenging activity, strong Ferric Reducing Antioxidant Power (FRAP) and moderate inhibition activity of linoleic acid oxidation. This study aimed to determine antioxidant activity and phenolic compound of Java Plum seed (Syzygium cumini L.) methanolic extract fractions. Phenolics compound identification using Thin Layer Chromatography (TLC) showed that all fractions (polar, semi-polar, and hydrolyzed semi-polar fraction) contained gallic acid, tannic acid and flavonol's rutin. HPLC-DAD analysis showed that its polar fraction contained 25 ppm flavonol's quercetine and $55181 \mathrm{ppm}$ flavonol's (+)-catechin, ethyl acetate fraction contained 54 ppm flavonol's rutin and 528 ppm (+)-catechine, while hydrolyzed ethyl acetate fraction contained 404 ppm Rutin and 28692 ppm (+)catechine.
\end{abstract}

Keywords: antioxidant (+)-catechine, Java Plum seed, methanolic extract

Introduction

Duwet (Syzygium cumini L.) is local name for Java plum, widely grown in many countries whose seed has been used for traditional medication, particularly to treat type-2 diabetes mellitus (Helmstadter, 2008; Kumar et al., 2010; Swami et al., 2012; Tupe et al., 2015). In several places in Indonesia, the seeds of subvar Genthong are roasted, ground, brewed and served as "Duwet coffee" for diabetes traditional treatment. Various in vitro study showed that Java plum seed extract exhibit strong antioxidant capacity as 1,1 diphenyl, 2-picryl hydrazyl (RSA-DPPH) free radical scavenger and ferric radical reducing agent (Vasi and Austin, 2009; Rydlewsky et al., 2013; Saha et al., 2013; Rohadi et al., 2016), strong scavenger against 2,2-azinobis, 3-ethylbenzothiazoline-6-sulphonate cation and nitro-oxide ( ${ }^{*} \mathrm{NO}$ ) radicals, as well as strong inhibition activity on lipid oxidation and $\alpha$-glucosidase (Vasi and Austin, 2009). Java plum seed is the potential natural antioxidant source (Vasi and Austin, 2009; 
Saha et al., 2013; Rydlewsky et al., 2013; Rohadi et al., 2016). Phenolic compounds are believed to be responsible for its strong antioxidant properties.

Java plum seeds shape is oblong, ovoid, with average weight of $1.67 \pm 0.31$ $\mathrm{g} / \mathrm{seed}, 2.18 \pm 0.15 \mathrm{~cm}$ long, about $1.03 \pm 0.05$ $\mathrm{cm}$ in diameter and $0.5 \pm 0.05 \mathrm{~cm}$ wide. Covered in red to pink fruit flesh, the seed is glossy white-pink at respective color scale $\left({ }^{*} \mathrm{~L},{ }^{*} \mathrm{a},{ }^{*} \mathrm{~b}\right)$ of $63.92,2.67,9.88$. It contains $6.63 \%(\mathrm{db})$ protein, lower than the flesh of $10.7 \%(\mathrm{db})$. It also contains $0.66 \%$ lipid, $3.28 \%$ ash, $75.4 \%$ total carbohydrate, $1.32 \%$ insoluble dietary fiber, and several sugars such as $3.25 \%(\mathrm{db})$ fructose, $2.60 \%(\mathrm{db})$ glucose, $0.19 \%(\mathrm{db})$ sucrose, $0.09 \%$ galactose, and small amount of raffinose ( $<128 \mathrm{ppm})$. Its mineral content is predominantly potassium (K) of $8.812 \mathrm{ppm}, 2.161 \mathrm{ppm}$ magnesium, $136.8 \mathrm{ppm}$ iron (Fe), $115 \mathrm{ppm}$ sodium $(\mathrm{Na}), 86$ ppm calcium ( $\mathrm{Ca}$ ), 35 ppm phosphor (P), and 5 ppm copper (Cu) (Rohadi et al., 2016).

Previous researches showed that the seed contains glycoside, hoursbolin (antimellin), ellagic acid, alkaloid (Quisumbing, 1951; Parmar et al., 2010), gallic acid, galloylglucose, 3-galloylglucose, 3,6-hexahydroxy diphenoylglucose, 4,6 hexahydroxydiphenoylglucose and $\beta$-sitosterol (Helmstadter, 2008; Swami et al., 2012; Rydlewsky et al., 2013). A research reported kaempferol and epicatechin claimed as first publication reported epicatechin content of Java plum seed (Rydlewsky et al., 2013). The seed for several years has attracting food researches to further study its functionality possibility (Rohadi et al., 2016).

\section{Materials and Methods Chemicals}

This research used methanol, ethyl acetate, Folin Ciocalteu reagent, gallic acid, tannic acid (Sigma Chemical Co. St. Louis USA) $(+)$-catechine, rutin, quercetin (Waco Pure
Chemical Industry-Osaka Japan), butylated hydroxyanisole/BHA (Sigma Chemical Co.), aqueous $\mathrm{Na}_{2} \mathrm{CO}_{3}$, Tween-40, $\mathrm{HCl}$, buffer phosphate $\mathrm{pH} 7$, ferrous chloride $\left(\mathrm{FeCl}_{2}\right)$, ferric chloride $\left(\mathrm{FeCl}_{3}\right)$, ammonium thiocyanate, $\mathrm{K}_{3} \mathrm{Fe}(\mathrm{CN})_{6}$, trichloroacetic acid (TCA), tungstophosphoric acid, 1,1-diphenyl-2-picryl hydroxyl radical (DPPH) and linoleic fatty acid, all in analytical grade. It also used rotary vacuum evaporator (IKA-RV 10 basic), vortex, incubator, water-bath shaker (Julabo SW 22), a UV-Visible spectrophotometer (UV-1601 Shimadzu) and HPLC-DAD Hitachi Auto sampler L-2200 (Berkshire, UK).

\section{Plant Authentication and Extracts}

\section{Preparation}

A dry powder of Java plum seed (Syzygium cumini Linn.) subvar "Genthong" ( $\leq 14 \%$ moisture content, 80 mesh) was obtained from optimum ripe fresh fruit harvested from several trees belong to residents of Semarang city, Jawa Tengah, Indonesia. The sample was authenticated and taxonomically identified by Laboratory of Plant Taxonomy, Faculty of Biology, Universitas Gadjah Mada. Approximately $50 \mathrm{~g}$ dried powder of Java plum was extracted using 50\% methanol at material:solvent ratio of $10: 1(\mathrm{v} / \mathrm{v})$, macerated in $100 \mathrm{rpm}$ waterbath shaker (Julabo SW 22) at room temperature $\left(28 \pm 2^{\circ} \mathrm{C}\right)$ and filtrated using Whatman paper. This process was repeated 3 times. Resulted extract was separated from the solvent using a rotary vacuum evaporator, to obtain a methanol free extract, which then subjected to partition fractionation using ethyl acetate solvent. A half volume of ethyl acetate fraction was subsequently hydrolyzed using $7 \% \mathrm{H}_{2} \mathrm{SO}_{4}(10: 1, \mathrm{v} / \mathrm{v})$ by reflux condenser for $4 \mathrm{~h}$. Ethyl acetate faction was separated and taken using separating funnel to obtain 3 fractions i.e. water fraction, ethyl acetate fraction, and hydrolyzed-ethyl acetate fraction. 


\section{Determination of Total Phenolic Compounds and Flavonoid Content}

Total phenolic content of MEJS was measured using Folin-Ciocalteu reagent (FCR) colorimetric method using spectrophotometer at $\lambda 765 \mathrm{~nm}$ according to the procedure applied by Ebrahimzadeh et al., (2008) with gallic acid as standard (g GAE/100 $g$ extract). Total flavonoid content was measured using spectrophotometer at $\lambda 415$ $\mathrm{nm}$ using protocols based on previous researches (Ebrahimzadeh et al., 2008; Vasi and Austin, 2009) with Quercetine as standard (g QE/100 g extract). Total tannin was also measured using spectrophotometer at $\lambda 725$ $\mathrm{nm}$ based on the method applied by Palici et al., (2005) with tannic acid as standard (g $\mathrm{TAE} / 100 \mathrm{~g}$ extract).

\section{DPPH Radical Scavenging Activity Assay}

Measurement of radical scavenging activity (RSA)-DPPH of MEJS according to procedure applied by Vasi and Austin (2009). Approximately $0.5 \mathrm{~mL}$ MEJS at various concentrations $(50-400 \mathrm{ppm})$ in $50 \%$ ethanol added with $0.5 \mathrm{~mL}$ 2,2-diphenyl-1-picryl hydroxyl radical (DPPH)-100 $\mu \mathrm{M}$ then incubated in the dark at room temperature $\left(37 \pm 2^{\circ} \mathrm{C}\right)$ for $30 \mathrm{~min}$, in triplicate for all samples. Its absorbance was read at $\lambda 517 \mathrm{~nm}$ using UV-Vis spectrometer (UV-1601 Shimadzu). Vitamin C, BHA, and Quercetin was used as a comparison. DPPH radical scavenging activity can be calculated as follows refereed (Vasi and Austin, 2009).

RSA-DPPH (\%) $=\left[\frac{1 \text { - sample absorbance }}{\text { control absorbance }}\right] \times 100 \%$

\section{Ferric Reducing Antioxidant Power (FRAP) Assay}

Ferric $\left(\mathrm{Fe}^{+3}\right)$ reducing antioxidant power (FRAP) was used as an indicator of electron transfer activity of phenolic compounds (Vasi and Austin, 2009). As much as $2.5 \mathrm{~mL}$ MEJS various concentrations (50-400 ppm) in ethanol was added with $2.5 \mathrm{~mL}$ buffer phosphate (0.2 M, pH 6.6) and $2.5 \mathrm{~mL}$ of $1 \%$ $\mathrm{K}_{3} \mathrm{Fe}(\mathrm{CN})_{6}$, incubated at $50^{\circ} \mathrm{C}$ for $20 \mathrm{~min}$. Subsequently, $2.5 \mathrm{~mL}$ of $10 \%$ trichloroacetic acid (TCA) was added to stop the reaction. After centrifugation using a vortex at 3.000 rpm for 10 minutes, $2.5 \mathrm{~mL}$ supernatant was taken and added with $2.5 \mathrm{~mL}$ distilled water and $0.5 \mathrm{~mL}$ of $0.1 \%$ ferric chloride $\left(\mathrm{FeCl}_{3}\right)$. Reducing activity of the sample was measured at $\lambda 700 \mathrm{~nm}$, with vitamin $C$ as a positive control. Increasing absorbance is an indicator of higher reducing power. The reduction percentage of the sample compared to control was calculated using the formula below:

$\%$ reducing activity $=\left[\frac{1-\text { sample absorbance }}{\text { control absorbance }}\right] \times 100 \%$

\section{Lipid Peroxidation in Linoleic Acid Emulsion Model System}

To measure peroxidation inhibition activity on linoleic acid, the analysis was carried out according to the method by Jayaprakasha et al., (2001). Initially, the emulsion was made by adding $0.28 \mathrm{~g}$ Tween40 and $50 \mathrm{~mL}$ buffer phosphate $(0.2 \mathrm{M} \mathrm{pH} 7.0$ ) into $0.28 \mathrm{~g}$ linoleic acid, mixed and homogenized. As much as $0.5 \mathrm{~mL}$ MEJS solution (Met-OH 60\%) in various concentrations (50-400 ppm) were mixed with $2.5 \mathrm{~mL}$ linoleic acid emulsion and $2.5 \mathrm{~mL}$ buffer phosphate (0.2 M pH 7.0) then incubated at $37^{\circ} \mathrm{C}$ for $120 \mathrm{~h}$ (5 days). Control was prepared as above without MEJS. From incubated solution, $0.1 \mathrm{~mL}$ was taken in $24 \mathrm{~h}$ interval, mixed with $5 \mathrm{~mL}$ of $75 \%$ ethanol, 0.1 $\mathrm{mL}$ of $30 \%$ ammonium thiocyanate, and 0.1 $\mathrm{mL}$ of $20 \mathrm{mM}$ ferrous chloride $\left(\mathrm{FeCl}_{2}\right)$ in $3.5 \%$ $\mathrm{HCl}$, then incubated in room temperature for $3 \mathrm{~min}$. After color changed to brick red, its absorbance was measured at $\lambda 500 \mathrm{~nm}$. BHA and Quercetine were used as a comparison. 
Antioxidant activity was calculated using Jayaprakasha et al., (2001) formula as follows:

Inhibition (\%) $=100-\left[\frac{\text { sample absorbance }}{\text { control absorbance }}\right] \times 100 \%$

\section{TLC Analysis of Tannic Acid}

As much as $100 \mathrm{mg}$ was taken from each extract, added with $1 \mathrm{~mL}$ of $50 \%$ ethanol, homogenized for 2 minutes using vortex and then centrifuged for 3 minutes. The liquid phase was taken using a micropipette, $10 \mu \mathrm{L}$ was spotted on silica gel 60 F254 plate. The plate was put into a saturated chamber with $150 \mathrm{~mL}$ ethyl acetate-acetic acid-formic acidwater (100-11-11-27, v/v/v/v) as the mobile phase. Elusion was done to upper-end limit and the plate was dried under UV ray. Staining was done using ferric chloride.

\section{TLC Analysis of Flavonoid Rutin}

Into the flask, $50 \mathrm{mg}$ of extract and $10 \mathrm{~mL}$ of $4 \mathrm{~N}$ hydrochloric acid were put for reflux hydrolysis using a condenser for 30 minutes. The mixture was cooled before extraction using $5 \mathrm{~mL}$ diethyl ether. Diethyl ether phase was taken prior to solvent removal using nitrogen spray. Sample spotting of $10 \mu \mathrm{L}$ was done on cellulose plate. Rutin was also spotted as a comparison. The plate was put into saturated chamber using $\mathrm{n}$-butanol:acetic acid:water $(3: 1: 1, v / v / v)$ as the mobile phase. Elusion was done to upper-end limit and the plate was dried and observed under UV ray. Staining was done using aluminum chloride.

\section{TLC Analysis of Gallic Acid}

From each extract, $100 \mathrm{mg}$ was taken and added with $1 \mathrm{~mL}$ methanol, homogenized using vortex for $2 \mathrm{~min}$ then centrifuged. The liquid phase was spotted for $20 \mu \mathrm{L}$ on silica gel 60 F254 plates before putting into a saturated chamber with methanol-10\% formic acid $(97: 3, v / v)$ as the mobile phase. Elusion was done until the upper-end limit of the plate before drying and observation under UV ray. Staining was done using ferric chloride.

\section{Determination of Gallic Acid, Catechine, and Rutin Content}

RP-HPLC Hitachi L-2200 (Berkshire, UK) equipped with LC-Diode Array Detector (DAD), auto sampler and column oven was used in this stage. Separation system consists of $5 \mu \mathrm{m}$ Hypersil ODS RP 18 Symmetry column (150 x $4.6 \mathrm{~mm}$ ). Acetonitrile-50 mM phosphate buffer set at pH 2.5 was set as elusion gradient system. Elusion gradient was made from variation between solvent $A$ (acetonitrile): solvent B (50 mM phosphate buffer) at $1 \mathrm{~mL} / \mathrm{min}$ rate. Mobile phase composition was initiated by $100 \%$ solvent $B$ (2 $\mathrm{min}$ ), followed by gradual increasing of solvent $A$ to $60 \%$ and decreasing solvent $B$ to $40 \%$ for $32 \mathrm{~min}$. Subsequently, the sample was re-equilibrated for $3 \mathrm{~min}$ similar to initial part (100\% solvent B). Thus, $35 \mathrm{~min}$ was needed per injection. This running was also equipped with mobile phase $0.45 \mu \mathrm{m}$ filtration system and compound detector at $\lambda$ $210 \mathrm{~nm}$ (Santagati et al., 2008).

\section{Determination of Quercetine Content}

RP-HPLC Hitachi L-2200 (Berkshire, UK) equipped with Phenomenex Luna $\mathrm{C}_{18}$ column ( $\varnothing 4.6 \mathrm{~mm} \times 250 \mathrm{~mm}$ ) and $5 \mu \mathrm{m}$ particle size was used. The mobile phase consisted of methanol:acetonitrile:water mixture (40:15: $45, \mathrm{v} / \mathrm{v} / \mathrm{v}$ ) contained $1 \%$ acetic acid, previously filtered using $0.45 \mu \mathrm{m}$ filter paper (Millipore). The flow rate and volume of injection were set at $1 \mathrm{~mL} / \mathrm{min}$ and $10 \mu \mathrm{L}$, respectively, using ultraviolet detection at $\lambda 368 \mathrm{~nm}$. Quantification of the target compound was conducted based on UV spectrum peak area ratio of the standard compound with the sample at similar tR (retention time) (Phani et al., 2010). 


\section{Determination of (+)-Catechine Content}

RP-HPLC Hitachi L-2200 (Berkshire, UK) equipped with Phenomenex Luna $\mathrm{C}_{18}$ column ( $\varnothing 4.6 \mathrm{~mm} \times 250 \mathrm{~mm}$ ) and $5 \mu \mathrm{m}$ particle size was used. The mobile phase consisted of methanol:acetonitrile:water mixture (40:15: $45, \mathrm{v} / \mathrm{v} / \mathrm{v}$ ) contained $1 \%$ acetic acid, previously filtered using $0.45 \mu \mathrm{m}$ filter paper (Millipore). The flow rate and volume of injection were set at $1 \mathrm{~mL} / \mathrm{min}$ and $10 \mu \mathrm{L}$, respectively, using ultraviolet detection at $\lambda \quad 279 \mathrm{~nm}$. Quantification of the target compound was conducted based on UV spectrum peak area ratio of the standard compound with the sample at similar tR (Zu et al., 2006).

\section{Statistical analysis}

Experimental results are expressed are as mean $\pm S D$. All measurement were conducted in triplicate, analyzed using analysis variance $(p<0.05)$. A significant difference was measured using by Duncan's Multiple range tests.

\section{Results and Discussion}

Preliminary phytochemical analysis of the methanolic extracts revealed the presence of phenolic compounds, reducing sugars, proteins, insoluble dietary fiber and some macro minerals such as potassium, magnesium, sodium and ferrum. Total phenolic referred to standard curve $\mathrm{y}=7.144 \mathrm{x}$ $0.034\left(r^{2}=0.986\right)$ was $45.99 \pm 0.25 \%$ (g GAE $/ 100$ $\mathrm{g}$ dry extract). Total flavonoid contents of $2.28 \pm 0.07 \%$ (g-Quercetin equivalent $/ 100 \mathrm{~g}$ dry extracts) was referred to standard curve $\mathrm{y}=$ $1.364 x+0.006\left(r^{2}=0.996\right)$. Total tannins of $26.9 \pm 0.07 \%$ (g-Tannic acid equivalents $/ 100 \mathrm{~g}$ dry extract) was referred to tannin standard curve $y=7.441 x+0.033\left(r^{2}=0.991\right)$ (Rohadi et al., 2016).

\section{Antioxidant activity}

Several concentrations $(50-400 \mu \mathrm{g} / \mathrm{mL})$ of $50 \%$ methanolic extract was obtained from
Syzygium cumini L. seed and tested for their in vitro antioxidant activity. It was observed that the test compounds scavenged free radicals in a concentration-dependent manner in all model (Table 1). The highest DPPH inhibition percentage was $93.51 \%$ at $400 \mu \mathrm{g} / \mathrm{mL}$, while the highest FRAP was $-4.05 \%$ (the negative value was caused by higher sample absorbance than reference absorbance). Inhibitory activity against lipid peroxidation was $60.37 \%$ at $96 \mathrm{~h}$ during initial incubation.

Oxidative degradation of lipid especially that induced by reactive oxygen species (ROS) lead to quality deterioration of food and could have harmful effects on health (Laguerre et al., 2007; Vasi and Austin, 2009). The natural antioxidant may offer resistance against the lipid autoxidation occurs by a freeradical chain reaction (Vasi and Austin, 2009).

The DPPH (1,1-diphenyl-2-picryl hydrazyl radical) assay have been widely used to determine the free radical-scavenging activity of various plants and pure compounds. DPPH is stable free radicals which dissolve in methanol and its color show characteristic absorption at $517 \mathrm{~nm}$.

When an antioxidant scavenges the free radicals by hydrogen donation, the colors in the DPPH assay mixture to become lighter. As presented in Table 1, DPPH inhibition percentage values were dose dependent, whereby they increased in the range on the tested concentration for the and the positive control (BHA). At the same concentrations $(400 \mu \mathrm{g} / \mathrm{mL}$ ) certainly, the DPPH inhibition of MEJS (93.05\%) was stronger than BHA (73.71\%).

The reducing power of a MEJS may serve as a significant indicator of its potential antioxidant activity. It can be seen that the reducing power percentage values of MEJS and the positive control (Vitamin C) were concentration-related and increase with the increase in sample concentration in the range 50-200 $\mu \mathrm{g} / \mathrm{mL}$. Meanwhile, the 
Table 1. Antioxidant properties of MEJS as measured by lipid peroxidation inhibition activity, DPPH scavenging, and FRAP

\begin{tabular}{ccll}
\hline \multirow{2}{*}{ Conc. $(\mu \mathrm{g} / \mathrm{mL})$} & \multicolumn{2}{c}{ Scavenging of free radicals $(\%)$} \\
& PoV $(96 \mathrm{~h})$ & DPPH & FRAP \\
\hline 50 & 49.63 & 83.513 & 52.53 \\
100 & 50.13 & 91.89 & 54.88 \\
150 & 51.09 & 92.21 & 52.34 \\
200 & 51.93 & 92.87 & -1.46 \\
400 & 60.37 & 93.045 & -4.05 \\
\hline Results are mean of triplicate & & &
\end{tabular}

absorbance value of Vitamin $C$ in the range 250-1000 $\mathrm{\mu g} / \mathrm{mL}$ showed weaker than MEJS absorbance value so that the percentage reduction of the sample as compare to standard was negative. The high tannin content of MEJS allegedly contributes on strong RSA-DPPH and FRAP assay. Zhang and Lin (2009) note that tannins extracted from Java plum fruits showed a very good DPPH radical scavenging activity and ferric reduction antioxidant power.

In $\mathrm{FeCl}_{2} / \mathrm{H}_{2} \mathrm{O}_{2}$ stimulated linoleic acid peroxidation system showed the MEJS in moderate inhibitory activity against peroxidation (60.4\%) and significantly lower $(p<0.05)$ than BHA, however, stronger than grape seed extract (the picture not showed).

\section{Identification of phenolic compounds using}

TLC

Aqueous MEJS was fractioned using separating funnel using ethyl acetate as solvent and one of the fractions (ethyl acetate fraction) was hydrolyzed using sulfuric acid (7\% $\mathrm{H}_{2} \mathrm{SO}_{4}$ ) based on method previously applied by Meena and Patni (2008), whereby 3 fractions were obtained, water, ethyl acetate, and hydrolyzed ethyl acetate fraction of sample. The results of phenolic compounds qualitative measurements by TLC are presented in Table 2.

Table 2. Phenolic compounds of MEJS fraction measured by TLC

\begin{tabular}{ccccc}
\hline \multirow{2}{*}{ No } & \multirow{2}{*}{ Fraction } & Compound & Rf & Results \\
\hline \multirow{3}{*}{1} & \multirow{3}{*}{ Water } & Flavonoid (Rutin) & 0.47 & $(+)$ \\
& & Phenolic (gallic acid) & 0.76 & $(+)$ \\
& & Tanin (tannic acid) & 0.74 & $(+)$ \\
\hline \multirow{3}{*}{2} & \multirow{3}{*}{ Ethyl acetate } & Flavonoid (Rutin) & 0.47 & $(+)$ \\
& & Phenolic (gallic acid) & 0.76 & $(+)$ \\
& & Tanin (tannic acid) & 0.74 & $(+)$ \\
\hline \multirow{3}{*}{3} & Hydrolyzed- & Flavonoid (Rutin) & 0.47 & $(+)$ \\
& Ethyl acetate & Phenolic (gallic acid) & 0.76 & $(+)$ \\
& & Tanin (tannic acid) & 0.74 & $(+)$ \\
\hline
\end{tabular}


Gallic acid determination. Silica gel plate 60 F254 (Al-sheet) previously spotted by the sample was put in a chamber filled with $200 \mathrm{~mL}$ mobile phase made from methanol:10\% formic acid (97:3, v/v). Visualization under UV ray using TLC scanner was conducted at $\lambda 254 \mathrm{~nm}$ and $365 \mathrm{~nm}$. Fluorescence was found in all 3 samples similar to reference (gallic acid) at retention factor $\left(R_{f}\right)$ of 0.76 , it was suspected that gallic acid was suspected to be present in all fractions.

Flavonoid rutin determination. Silica gel plate 60 F254 (Al-sheet) previously spotted by the sample was put in a chamber filled with $200 \mathrm{~mL}$ mobile phase made from butanol:acetic acid:water (3:1:1, v/v/v). Visualization under UV ray using TLC scanner was conducted at $\lambda 254 \mathrm{~nm}$ and $365 \mathrm{~nm}$. Fluorescence was found in all 3 samples similar to reference (rutin) at $R_{f}$ of 0.47 . It indicated that water, ethyl acetate, and hydrolyzed ethyl acetate contained compound suspected as rutin.

Tannic acid determination. Silica gel plate 60 F254 (Al-sheet) previously spotted by the sample was put in a chamber filled with $200 \mathrm{~mL}$ mobile phase made from ethyl acetate-formic acid-acetic acid-water (100-1111-27, v/v/v/v). Visualization under UV ray using TLC scanner was conducted at $\lambda 254 \mathrm{~nm}$ and $365 \mathrm{~nm}$. Fluorescence was found in all 3 samples similar to reference (tannic acid) at $R_{f}$ of 0.74 indicated that water, ethyl acetate, and hydrolyzed ethyl acetate contained compound suspected as tannin.

\section{Identification of Phenolic Compounds using HPLC-DAD}

To measure the quantity and the type of phenolic compounds of MEJS, the sample was analyzed using HPLC referred to retention time (tR) and the peak of phenolic compounds standard, which was phenolic's gallic acid, flavonol's rutin and quercetin, and flavanol's $(+/-)$ catechin. Analysis of gallic acid, catechin, and rutin was done based on the method applied by Santagati et al., (2008), quercetin by those of Phani et al., (2010), while quantitative analysis of catechin was done according to $\mathrm{Zu}$ et al. (2006). The results are presented in Table 3.

Identification of flavonoid's rutin. Analysis of phenolic compound using HPLC showed that gallic acid, catechin, and rutin were not found in water fraction. In ethyl acetate fraction, gallic acid and catechin were also not found, but $54.1 \mathrm{ppm}(\mathrm{mg} / \mathrm{L})$ rutin was found. Similarly, in hydrolyzed ethyl acetate fraction, there was only rutin found of 404 ppm (mg/L), as seen in Fig. 1 .

Table 3. Phenolic compound of MEJS fractions

\begin{tabular}{lcccc}
\hline \multirow{2}{*}{ Fraction } & \multicolumn{4}{c}{ Concentration (mg/L) } \\
\cline { 2 - 4 } & Gallic acid & Rutin & Quercetin & (+)-Catechin \\
\hline Water & n.d & n.d & 25 & 55181 \\
Ethyl acetate & n.d & 54.1 & n.d & 258 \\
$\begin{array}{l}\text { Hydrolyzed } \\
\text { Ethyl acetate }\end{array}$ & n.d & 404 & n.d & 28692 \\
\hline n.d = not detected & & &
\end{tabular}



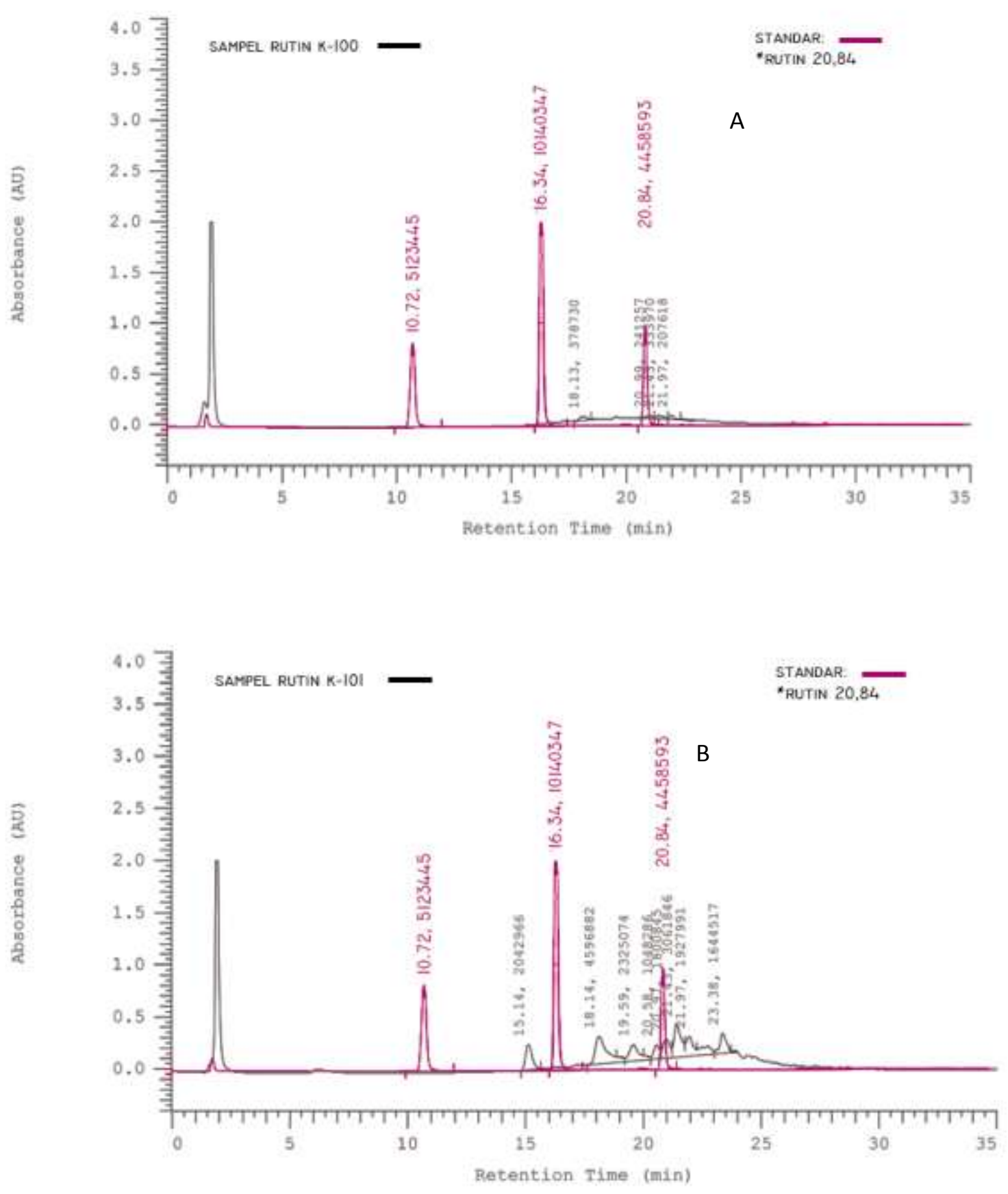

Fig 1. Chromatogram confirmed gallic acid $(t R=10.72)$, catechin $(t R=16.34)$ and rutin $(t R=20.84)$ were not detected (n.d) in water fraction (A), but $54.1 \mathrm{ppm}$ and $404 \mathrm{ppm}$ of flavonoid's rutin was found in ethyl acetate fraction and hydrolyzed ethyl acetate fraction, respectively (B). 


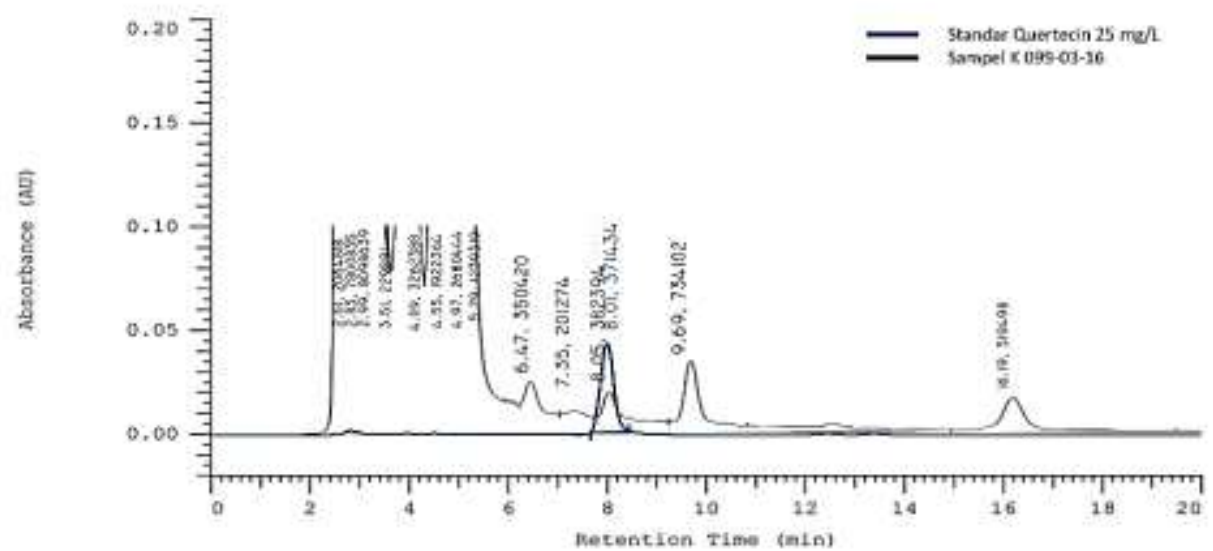

Fig. 2 Quercetin (insert) was detected in water fraction of MEJS (25 ppm), but not detected in two other fractions (ethyl acetate and hydrolyzed ethyl acetate fraction), tR $=8.05$

Identification flavonoid's quercetin. Quantitative analysis of flavonoid's quercetin was done according to the method applied by Phani et al. (2010) on all three fractions, compare to chromatogram of quercetin ( $t R=$ 8.05) as standard. Water fraction chromatogram showed that $25 \mathrm{ppm}(\mathrm{mg} / \mathrm{L})$ quercetin was found, but not in other two fractions (Fig. 2).

The presence of quercetin in Java plum seed was confirmation of previous researches (Baliga et al., 2011; Swami et al., 2012). Flavonoid tends to dissolve in water and other polar solvents such as methanol, ethanol, ethyl acetate and their mixture, which classified them as a suitable solvent to extract plant flavonoid (Heim et al. 2002; Harborne, 2006; Durackova, 2008). Quercetine was not found, but another flavonol family such as kaempferol of $236.98 \pm 5.63 \mathrm{mg} / 100 \mathrm{~g}$ with strong absorbance at $\lambda 243 \mathrm{~nm}$ (Rydlewsky et al., 2013).

Identification of (+)-catechin. Quantification of tannin (+)-catechin was done according to the method applied by Zu et al., (2006) on 3 fractions. Chromatogram of water fraction (Fig. 3a) showed that catechin was found for $55181 \mathrm{ppm}$ (mg/L). Catechin was found in ethyl acetate fraction (not presented in the figure) and hydrolyzed ethyl acetate fraction (Fig. 3b) of $258 \mathrm{ppm}(\mathrm{mg} / \mathrm{L})$ and $28692 \mathrm{ppm}(\mathrm{mg} / \mathrm{L})$, respectively, with standard catechin as a reference $(t R=2.79)$.

The presence of tannin in duwet with its antioxidative property was previously reported (Mura et al., 2000; Zhang and Lin, 2009). Rydlewsky et al., (2013) were the first study reported epicatechin content in Java plum seed of $48.14 \pm 0.57$ (mg/100 g), which did not found in other parts of the fruit (pulp and peel). Catechin is commonly found in tea leaves (Heim et al., 2002; Brewer, 2011), grape seed, onion and its family (Brewer, 2011).

There was significant increasing of catechin found in ethyl acetate and its hydrolyzed fraction, from $258 \mathrm{ppm}(\mathrm{mg} / \mathrm{L})$ to $28692 \mathrm{ppm}(\mathrm{mg} / \mathrm{L})$. That higher content of $(+)-$ catechin was caused by hydrolysis of flavan-3ols, either in monomer form (gallocatechin) or its oligomer and polymer (proanthocyanidins). Tavares et al., (2016) noted 8 monomers of flavan-3-ols were found in edible part of duwet (peel and pulp), which were catechin, epicatechin, gallocatechin, epigallocatechin, epicatechin-3-0 gallate, catechin-3-0-gallate, epigallocatechin-3-0-gallate, and gallocatechine-3-0-gallate. 


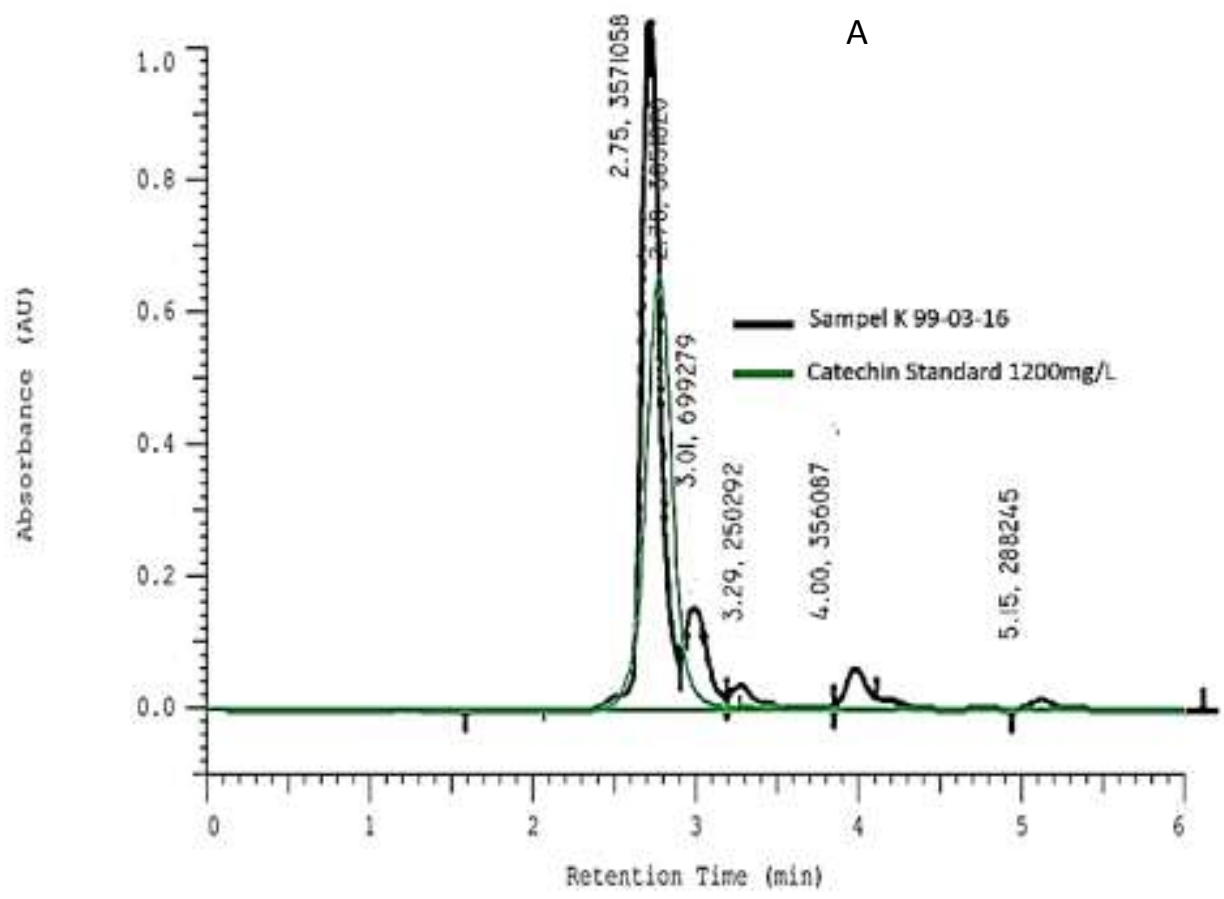

B

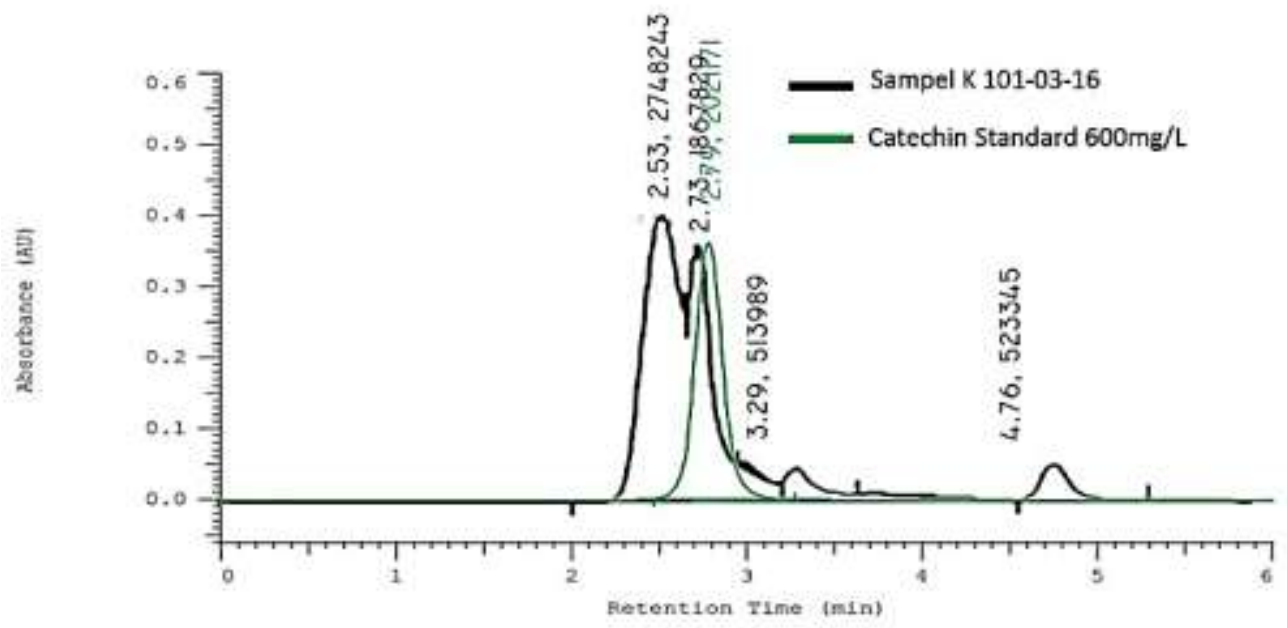

Fig. 3 The high amount of flavanoids (+)-catechin was found in MEJS in water fraction (A) as well as ethyl acetate and hydrolyzed ethyl acetate fraction (B).

\section{Conclusion}

MEJS exhibited strong antioxidant activity as DPPH radical scavenger and ferric reducing agent, with moderate lipid peroxidation inhibition activity, with flavonoid's rutin and quercetin and abundant tannin (+)-catechin responsible for the action. It can be concluded that Java plum seed is the potential natural antioxidant source.

\section{Acknowledgment}

The authors thank the Directorate General of Higher Education Ministry of Research Technology and Higher Education of the Republic of Indonesia for financial support. 


\section{References}

Baliga, M.S., Baht, H.P., Baliga, B.R.V., Wilson, R. and Palatty, P.L. 2011. Phytochemistry, tradisional uses and pharmacology of Eugenia jambolana Lam. (black plum): A review. Food Research International. 44:1776-1789.

Brewer, M.S. 2011. Natural Antioxidant: Source, Compounds, Mechanisms of Action, and Potential Application. Comprehensive Reviews. Food Science and Food Safety. 10: 221-247.

Durackova, Z. 2008. Oxidants, Antioxidants and Oxidative Stress. In "Mitochondrial Medicine:

Mitocondrial Metabolisme, Diseases, Diagnosis and Therapy". ed. Anna Gvozdjakova, pp. 19-54. SpringerVerlag, New York.

Ebrahimzadeh, M.A., Pourmorad, F. and Hafezi, S. 2008. Antioxidant activities of Iranian Corn Silk. Turkish Journal of Biology. 32: 43-49.

Harborne, J.B. 2006. "Metode Fitokimia: Penuntun Cara Modern Menganalisis Tumbuhan". Institut Teknologi Bandung, Bandung.

Heim, K.E., Tagliaferro, A.R., and Bobilya, D.J. 2002. Flavonoid antioxidants: chemistry, metabolism and structureactivity relationships. Review. Journal of Nutritional Biochemistry. 13:572584.

Helmstadter, A. 2008. Syzygium cumini (L.) Skeel (Myrtaceae) against diabetes125 years of research. Pharmazie. 63 (2):91-101.

Jayaprakasha, G.K., Singh, R.P. and Sakariah, K.K. 2001. Antioxidant activity of grape seed (Vitis vinifera) extracts on peroxidation models in vitro. Food Chem. 73:285-290.

Kumar, A., Lakshman, K., Jayaveera, K.N., Tripathi, S.N.M. and Satish, K.V. 2010.
Estimation of Gallic Acid, Rutin and Quercetin in Terminalia chebula by HPTLC. Jordan Journal of Pharmaceutical Sci. 3(1): 63-67.

Laguerre, M., Lecomte, J., and Villeneuve, P. 2007. Evaluation of the ability of antioxidant to counteract lipid oxidation: Existing methods, new trends and challenges: A review. Progress in Lipid Research. 46:244282.

Meena, M.C. and Patni, V. 2008. Isolation and Identification of Flavonoid "Quercetine" from Citrullus colocynthis (Linn.) Schrad. Asian J. Exp. Sci. 22 (1):137-142.

Mura, K., Shiramatsu, H. and Tanimura, W. 2000. A Substance Inhibiting the Growth of Lactic Acid Bacteria in Duhat (Syzygium cumini Skeel) Bark. Journal Biocontrol Science. 5(1):33-38.

Palici, I., Tita, B., Ursica, L., and Tita, D. 2005. Method for Quantitative Determination of Polyphenolic Compounds and Tannins from Vegetal Products. Seria F Chemia. 8:21-32

Phani, Ch.R.S., Vinaykumar, Ch., Rao, K.U. and Sindhuja, G. 2010. Quantitative Analysis of Quercetin in Natural Sources by RP-HPLC. International Journal of Research in Pharmaceutical and Biomedical Science. 1(1):19-22.

Parmar, J., Sharma, P. and Verma, P. 2010. Chemopreventive Action of Syzygium cumini on DMBA-Induced Skin Papillomagenesis in Mice. Asian Pacific Journal of Cancer Prevention. 11(1): 261-265.

Quisumbing, E. 1951. Medical Plant of the Philippines. Tech. Bui. Department of Agricultural and Natural Resources, Manila. In "Jamun (Syzygium cumini L.): A Review of Its Food and Medicinal Uses". ed. Swami, S.B., 
Thakor, N.S.J., Patil, M.M. and Haldankar, P.M. 2012. Food and Nutrition Science. 3:1100-1117.

Rohadi, Raharjo, S., Falah, I.I., and Santoso, U. 2016. Antioxidant activity of duwet (Syzygium cumini Linn.) seed extract Genthong varieties on lipid peroxidation models in vitro. Journal of Agritech 36 (1): 30-37.

Rydlewsky, A. A. de Morais, D.R., Rotta, E.M., Clause, T. and Visentainer, J.V. 2013. Determination of bioactive compounds, antioxidant activity and physical and chemical composition of different parts of four Brazilian fruits. State University of Maringa, Postgraduate Program, Colombo, Brazil.

Saha, R.K., Zaman, N.M., and Roy, P. 2013. Comparative evaluation of the medicinal activities of methanolic extract of seed, fruit pulp and fresh juice of Syzygium cumini in vitro. Journal of coastal Medicine. 1(4):288296.

Santagati, N.A., Salerno, L., Attaguile, G., Savoca Fr., and Ronsisvalle, G. 2008. Simultaneous Determination of Catechins, Rutin, and Gallic Acid in Cistus Species Extracts by HPLC with Diode Array Detection. Journal of Chromatographic Sci. 46:150-156.

Swami, SB., Thakor, NS., Patil, MM., and Haldankar, PM. 2012. Jamum (Syzygium cumini (L.)): A review of its food and medicinal uses. Food and Nutrition Sci. 3(8):1100-1117.

Tavares, I.M.C., Lago-Vanzela, E.S., Rebello, L.P.G., Ramos, A.M., Gomez-Alonzo, S., Garcia-Romero, E., Da-Silva, R., and Hermosin-Gutierrez, I. 2016. Comprehensive study of the phenolic composition of the edible part of Jambolan fruits (Syzygium cumini (L.) Skeel). Food Research International. 82:1-13.

Tupe, R.S., Kulkarni, A., Adeshara, K.M., Shaikh, S., Shah, N. and Jadhav, A. 2015. Syzygium jambolanum and Cephalandra indica homeopathic preparation inhibit albumin glycation and protect erythrocytes: an in vitro study. Homeopathy. 104 (3): 197-204.

Vasi, S. and Austin, A. 2009. Antioxidant Potential of Eugenia jambolana Lam. Seeds. Journal of Biological Sciences. 9(8): 894-898.

Zhang, L.L., and Lin, Y.M. 2009. Antioxidant tannins from Syzygium cumini fruit. African Journal of Biotechnology. 8(10):2301-2309.

$\mathrm{Zu}$, Y., Li, Ch., Fu, Y., and Zhao, and Chunjian. 2006. Simultaneous determination of catechin, rutin, quercetin, kaempferol and isorhamnetin in the extract of sea buckthorn (Hippopae rhamnoides L.) leaves by RP-HPLC with DAD. Journal of Pharmaceutical and Biomedical Analysis. 41: 714-719. 